\title{
MARCAS DE LO TRANSGENERACIONAL EN ALGUNOS VERSOS DE "EL LIBRO DEVORADO”"
}

\author{
José Matamala Pizarro \\ Pontificia Universidad Católica de Valparaíso \\ Valparaíso, Chile \\ jose.matamala@pucv.cl
}

RESUMEN / ABSTRACT

\begin{abstract}
Este artículo analiza algunos versos contenidos en "El Libro Devorado" del poeta chillanense Pablo Apellidos. El libro fue entregado al presbítero de la parroquia Santo Domingo como fundamento de su apostasía, para luego ser publicado el año 2015 como creación literaria. La revisión de los versos se contrasta con las reflexiones de Sigmund Freud respecto al papel del traspaso filogenético en el devenir histórico del sujeto. Dentro de ese traspaso se encuentran elementos de corte transgeneracional que delinean las adhesiones de las personas a creencias, ideales, malestares, entre otros. La religión es una de ellas, por lo que en el libro el poeta Pablo Apellidos busca desasirse de la marca religiosa signada en su bautizo y del cristianismo como institución; para finalmente salvaguardar las enseñanzas de Jesús y terminar ubicado del lado de la esperanza mesiánica.
\end{abstract}

PALABRAS ClaVE: fantasías, representación religiosa, memoria, traspaso transgeneracional, esperanza mesiánica.

\section{MARKS OF THE TRANSGENERATIONAL IN SOME VERSES OF "EL LIBRO DEVORADO"}

This article analyzes some verses contained in "El Libro devorado" by the poet Pablo Apellidos from Chillan. The book was given to the presbyter of Santo Domingo parish, as the foundation of his apostasy, to be later published in 2015 as a literary creation. The revision of the verses is contrasted with Sigmund Freud's reflections regarding the role of the phylogenetic

1 El presente trabajo fue realizado gracias al financiamiento de la Beca de Postgrado PUCV 2018. El autor participa de los grupos de investigación TRASAS PUCV y Clínica del Trabajo, Valparaíso. 
transfer in the historical evolution of the individual. Within this transfer there are elements of a transgenerational cut delineating the adhesions of people to beliefs, ideals, and discomforts, among others. Religion is one of them, so in the book the poet Pablo seeks to release himself from the religious mark signed in his baptism and of Christianity as an Institution; to finally safeguard the teachings of Jesus and end up on the side of messianic hope.

KEYWORDS: fantasies, religious representation, memory, transgenerational transfer, messianic hope.

Recepción: 12/04/2018

Aprobación: 09/08/2018

\section{INTRODUCCIÓN}

En la reflexión freudiana, la cuestión transgeneracional no aparece bajo esa denominación. Sin embargo, es posible apreciar una aproximación a dicha problemática cuando Freud se pronuncia sobre el papel de las influencias filogenéticas en la constitución de la vida anímica. La historia filogenética de la especie se apuntala como un aspecto constitucional en la vida psíquica del ser humano, por lo que el devenir histórico de la humanidad deja sus marcas en el psiquismo de cada uno de los sujetos.

La organización de la vida humana reconoce en la cultura un puntal de posibilidad para que el sujeto se desarrolle y sobreviva. En ella se alimenta y se apropia de la historia que le transmiten sus familiares, parientes u otros; lo transgeneracional se aprecia con nitidez y se concretiza en el apego a las religiones, los intereses laborales y políticos, las creencias sobre la sexualidad y el género, entre otros.

Las marcas que imprime la historia trasmitida de generación en generación puede orientar al sujeto en aras de sus más altos ideales o en sus más notorias dolencias y malestares. Es lo que se visualiza en el análisis de algunos pasajes de la obra de Pablo Apellidos, joven poeta ñublensino, de quien tomé para este trabajo su escrito El Libro devorado (2015), por estar muy clara la influencia de lo transgeneracional en su adhesión a la religión católica, hasta que en diciembre de 2013 decidió dimitir formalmente a su fe y por ello solicitó su renuncia al presbítero de la capilla Santo Domingo.

Su libro es el testimonio de una apostasía; con él busca deshacerse de la influencia de lo religioso que le fue signada por su familia con el nombre reivindicativo del apóstol Pablo. En sus 46 poemas intenta desprenderse de la marca religiosa que le pesaba como estigma; busca recuperar el valor humano trascendente y espiritual de Jesús que es pervertido cotidianamente por el discurso oficial sacerdotal. 
Considerando lo anteriormente expuesto, fue del todo estimulante analizar algunos de los pasajes de la obra a la luz de las reflexiones freudianas sobre el papel de las huellas transgeneracionales que cimentan el aparato psíquico. En los versos destacados se pudo descubrir la impronta que dejó el padecer religioso del poeta y como éste utilizó lo literario para cobrarse revancha del uso malicioso de la causa cristiana y propugnar el rescate del ejemplo de Cristo. En lo que sigue se presenta el resultado de dicho análisis.

\section{FREUD Y ALGUNAS IDEAS SOBRE EL PROBLEMA DE LO TRANSGENERACIONAL}

De forma temprana, Sigmund Freud se refirió al problema de la memoria en la constitución de la vida anímica. En el conocido Proyecto de una psicología para neurólogos (1950 (1890)) señaló que cualquier teoría psicológica digna de atención debe brindar una explicación de ella. Allí menciona que la memoria tiene cierta independencia de la conciencia, por lo que el registro de la percepción va ligada a la última, mientras que el recordar se asocia con la primera. La memoria contiene aquellas vivencias que siguen teniendo efecto dada la magnitud con que éstas se registraron y con la frecuencia que se vuelven a repetir. El recordar sigue un curso de dirección a la inversa, hacia atrás, que choca con otras vivencias que hasta entonces eran inconscientes, que no habían tenido valor psíquico en el momento, pero que por el hecho de ser activadas con posterioridad [Nachträglichkeit] se dotan de sentido. Se vuelven cualitativamente significativas para el sujeto porque esas vivencias impresionaron, dejaron huellas.

En el manuscrito $L$ enviado el 2 de mayo de 1887 a W. Fliess, Freud comentó que el recordar puede someterse a una refinación. Ésta se cumple a través de las fantasías, las que se forjan gracias a las cosas que fueron percibidas por el sujeto a través del aparato auditivo y se valorizan de manera póstuma. La fantasía tiene un rol combinatorio, toda vez que anuda la vivencia y lo oído, lo pasado - de la historia de los padres y sus antepasados-con lo que el sujeto observó por sí mismo.

En A propósito de las críticas a la "neurosis de angustia" (1895) refiere una interesante ecuación sobre los factores etiológicos que inciden en las neurosis y que vuelve a retomar en La herencia y la etiología de las neurosis (1896) y en Nuevas puntualizaciones sobre la neuropsicosis de defensa (1896). Las causas desencadenantes, las condiciones, las causas específicas y las causas concurrentes forman parte de la ecuación. 
Destaca que como condiciones "se definen los factores que de estar ellos ausentes el efecto nunca se produce, pero son incapaces de generarlo por sí solos, no importa cuán grande sea la escala en que estén presentes. Para aquel efecto necesitan todavía de la causa específica" (Freud 135).

La causa específica otorga potencia para la realización de determinados efectos. Se puede argumentar que las condiciones poseen un carácter de estado existente antiguo y poco variable, mientras que la causa específica es más actual y dúctil.

Se mencionó anteriormente que las fantasías pueden refinar la actividad del recordar y anudan las vivencias pasadas con la valorización póstuma que realiza el sujeto. Para Freud, existen ciertas fantasías que son compartidas por todos los sujetos, a ellas les llamó fantasías primordiales [Urphantasien]. Éstas, dentro de la ecuación etiológica, forman parte de las condiciones, toda vez que cumplen con el atributo de ser antiguas y poco variables en su realización entre los diferentes sujetos.

Laplanche y Pontalis (1967 (2013)) destacan que para Freud estas estructuras fantaseadas típicas - sobre la vida intrauterina, escena originaria, la castración, la seducción- organizan la estructura de la fantasía y son universales porque se transmiten filogenéticamente. Es por aquello que en textos como La interpretación de los sueños (1899(1900)) Freud recurre a la saga de Edipo para representar el drama al que todo sujeto está expuesto por dirigir sus mociones sensuales hacia sus padres; en Historia de una neurosis infantil (caso del «hombre de los lobos») (1914 (1918)) analiza las consecuencias de la escena primordial [Urszene] en la vida anímica de Serguéi Pankéyev; en Inhibición, síntoma y angustia (1926 (1925)) retoma sus ideas sobre el impacto del nacimiento y su rol en la articulación de la angustia por la ruptura del equilibrio en la vida intrauterina; en Análisis de la fobia de un niño de cinco años (1909) regresa a este elemento histórico destacado en un pasaje de la Interpretación de los sueños y lo analiza a la luz de la conciencia de culpa que surgió en la vida del pequeño Hans a propósito del complejo de castración.

Resumiendo sobre lo analizado hasta esta parte, se tiene sobre el problema de la memoria que está atiborrada de experiencias que cobran sentido por el recordar. Este proceso se refina, se modula, por la acción de la fantasía. Las fantasías tienen así un doble sustento histórico, primero, se afincan en situaciones que fueron vivenciadas por el sujeto e internalizadas por un órgano sensorial -el que prima es el auditivo-y segundo, se sostienen en elementos filogenéticos que son más antiguos que la existencia del sujeto -ya que son 
patrimonio de la historia de la humanidad-y que tienen sus efectos en la vida de éste porque actúan como condiciones que forjan su vida anímica. A las primeras, Freud en La interpretación de los sueños las identificó como los restos diurnos que juegan un notable papel en la actividad del aparato psíquico, mientras que a las segundas las llamó fantasías primordiales y bosquejó su influencia en los textos citados anteriormente.

El traspaso de la historia, su transmisión transgeneracional, se asienta en estas rúbricas de la fantasía que merodean la acción del recuerdo y la memoria. Se favorecen de experiencias vividas como de la huella del desarrollo de la humanidad. Las marcas de la historia impresionan al sujeto y lo motivan, con efecto póstumo, a hacer algo. La tramitación de ellas es exigida por el aparato psíquico con arreglo a su contacto con la realidad. El sujeto se enfrenta a ella y tiene casi nulas probabilidades de soportarla aislado de otros. Para tramitar las marcas del traspaso de la historia, la vida en común con otros, la cultura le exige ciertas renuncias. A contrapelo de su deseo, el sujeto debe sacrificar parte de las fuerzas que lo atraen a repetir aspectos de sus fantasías o debe adaptarse a compartir ilusiones sustitutivas que toman fuerza de ellas. Esto es lo que analiza Freud en sus textos El porvenir de una ilusión (1927) y El malestar en la cultura (1930 (1929)). En ambos considera que las representaciones religiosas - a propósito del análisis de los versos del poeta Pablo Apellidos- son ilusiones, cumplimientos de deseos antiguos e intensos, por ejemplo, como el deseo de ser protegido frente a la experiencia de desvalimiento. Las fantasías e ilusiones son atributos de la memoria del desarrollo del sujeto y de sus parientes en tanto miembros de una especie y una cultura determinada.

\section{EL CREADOR LITERARIO, EL MALESTAR Y EL INTENTO DE RENUNCIA A LA MARCA}

En El creador literario y el fantaseo (1908 (1907)) Freud reconoce que la fantasía puede tomar un estatuto muy serio para quien emprende un trabajo creativo. La labor toma fuerza de ellas, extrae la potencia afectiva para que la actividad se ejecute con algún grado de goce. La sustitución - movilizada por estos grandes montos de afectos- de la ilusión a la creación permite que se tramiten las fantasías en un territorio donde el sujeto tiene capacidad de dirección y control. El trabajo creativo, aunque depositario de la canalización de las fantasías, tiene realidad efectiva para quien lo ejecuta. Aquello se 
aprecia en el trabajo del poeta que se comporta de igual forma que el niño que realiza juegos [Spiel]: se crea un mundo de fantasía que toma en serio y que en sus versos escenifica en palabras que son susceptible de figuración a través del juego de placer [Lustspiel] y juego de duelo [Trauerspiel] y que lo señalan como actor dramático o el que juega al espectáculo [Schauspieler]. En la actividad poética, las cosas que no son reales pueden deparar un placer a través del juego de la fantasía poética, así como también las impresiones penosas pueden ser fuentes de goce para el poeta y para otros que leen o escuchan las figuraciones contenidas en los versos.

En la creación literaria es posible identificar las huellas de las influencias del devenir histórico del ser humano. A través del juego que se pone en escena en los versos, el poeta figura un narración, hace algo con los eventos de su vida que lo impresionaron. La actividad creativa, al igual que el juego infantil, es una acción que solo por posterioridad permite la obtención de goce. Como comparte una ligazón familiar con otros sujetos, el poeta comunica el producto de su trabajo a otros, le muestra a la cultura lo que ella le hizo padecer o gozar y, además, en su obra, recompone y ajusta cuentas con las privaciones o satisfacciones. Es por esa razón que el poeta se toma muy en serio la creación literaria. En su trabajo se permite abrir vetas para pensar un mundo nuevo.

El poeta Pablo Apellidos en su apostasía religiosa concentrada en " $E l$ libro devorado" (2015) intenta desasirse del malestar. Su obra es un juego del duelo [Trauerspiel] que discurre sobre el transitar de cuarenta y seis poemas - número similar a la cantidad de libros del Antiguo Testamentoque operan señalando la pavimentación de un camino de reivindicación de la causa defendida por Jesús. Para ello, renuncia a su fe validada por la Iglesia a través del sacramento del bautizo y fustiga con energía a los representantes de la institucionalidad. El malestar, regresando a las ideas vertidas por Freud en El porvenir de una ilusión y en El malestar en la cultura, se dirige hacia la representación religiosa que forjó un mundo - una realidad-donde el poeta experimentó las vilezas de aquellos que en nombre de Cristo propugnan el sometimiento. Las ilusiones y fantasías que debieron protegerlo de la hostilidad del mundo externo fracasaron, toda vez que el proyecto religioso se le mostró como una acentuación de la experiencia de desvalimiento. Se aprecia que la marca, la signatura de la historia religiosa montada en su experiencia de desarrollo biográfico es significada como un estigma que merece el trato poético necesario para su renuncia. 
Para comprender lo anterior, se analizan algunos versos de la obra del poeta. Se sigue el camino emprendido en su apostasía infiriendo que ésta se guía bajo la siguiente línea de producción: a) La marca religiosa y sus efectos en la desilusión del poeta de la representación religiosa que acentúa una crítica al aprovechamiento y sometimiento de la Iglesia y que potencia su adhesión a la reivindicación de la obra de Jesús.

ANÁLISIS DE LA LÍNEA DE PRODUCCIÓN DE LA APOSTASÍA: MARCA, DESILUSIÓN Y REIVINDICACIÓN

En el cuarto poema, se observan los siguientes versos

Me marcaron como Pablo, pero soy la burra de Balaam ¿Por qué me ha azotado tres veces, su majestad?

Ya no quiero ser Pablo ahora soy la burra soy la lengua de fuego sobre mi propia cabeza y mi rebuzno la palabra de Dios (10)

Como portador del nombre Pablo, lo que busca el poeta en los versos del cuarto poema es marcar distancias con la estampa de la conversión azuzada por su familia a través del nombre. Es menester recordar que el apóstol Pablo fue un converso a la fe cristiana, toda vez que antes de su militancia en ella, fue un fariseo. Su nombre precristiano era Saulo, conocido ortodoxo y persecutor del cristianismo. Su conversión se produjo porque el mismo Jesús se le apareció y le reprochó su conducta; con ello pasó a convertirse en el apóstol de los gentiles (no judíos e indiferentes), donde encontró un gran nicho para su prédica. En su empresa predicativa, el apóstol Pablo decidió entregar su vida a sufrir por Cristo, más aún si eso se vinculaba con la defensa de la Iglesia. Finalmente, cuando estuvo en la cárcel, sintió que lo había abandonado y fue condenado a muerte bajo la pena de decapitación.

Al parecer, al poeta le parece ominoso el pasaje de Pablo a la defensa corporativa de la Iglesia, no así la obra de Cristo. De lo que se quiere desprender con la renuncia de su nombre es de la misión de conservación y reproducción de la Iglesia, mas no de la lucha librada por Jesús. Tiene sentido para el poeta el sufrimiento de Cristo, pero no la pérdida de la vida por una institución que abandona y permite que los hombres pierdan la cabeza. Por eso prefiere ser 
la burra de Balaam, puesto que ella fue capaz de ver algo que su dueño no pudo: el deseo -manifestado en un ángel- de Dios para que no se maldijera a su Pueblo. El poeta no quiere ser un apóstol burócrata de la Iglesia, sino más bien una existencia que comprende los deseos de protección frente a la ignominia que dirige ésta hacia el Pueblo. Se siente culpable por portar en su nombre un aspecto que releva el rol burocrático del apóstol; prefiere usar el nombre precristiano Saulo para dirigir su ira contra la infamia del cristianismo como religión. Esta elección se observa en el poema cuarenta y cuatro

Que se desmarque a Pablo que ha gritado mi nombre

déjenlo libre

que vuelva a ser Saulo

y me persiga otra vez (50)

Lo que busca es conservar el vértice del apóstol Pablo que defiende la obra de Cristo y que persigue con furibunda perspicacia a aquellos que sostienen las acciones institucionales del cristianismo. Quiere rescatar la historia previa de Pablo -cuando era Saulo- para energizarse y tener coraje para criticar con vehemencia la obra de la Iglesia. Conservando al Pablo severo, el poeta se inviste de valor para renunciar a la marca de la representación religiosa y al traspaso de la influencia transgeneracional para actuar como guardia institucional de la Iglesia. Mientras que conservando al Pablo gentil, el poeta busca defender la historia y obra de Cristo. Admite que Jesús es digno de su confianza y amor; se indigna al observar que la Iglesia no ha sacralizado su ejemplo; está desilusionado. La marca de la historia tiene un doble efecto, su nombre le causa rechazo porque le recuerda el dolor y culpa que siente por los prejuicios que la Iglesia ha causado al Pueblo, mientras que también su nombre le recuerda que él puede reconstruir, en vistas de ideales gentiles y humanos, la verdadera obra de Cristo. Esta postura mesiánica se aprecia en el poema diecisiete.

No diré nada más sobre mis persecuciones

por ser un niño iluminado

y aceptaré mi condición como buen hijo de Abraham.

Me bautizaré a mí mismo como un Dios imperfecto

me hundiré en el agua

me ahogaré en el agua

y volveré a nacer en ésta 
seré el pez que se dibujaba en la tierra

seré la vasija que contiene el agua

que contiene una nueva era

Las campanas de la Iglesia se apagarán

y podremos al fin escuchar a los gorriones

Encontraremos en estos un llamado auténtico (23)

Las alusiones a la Urphantasie de la vida intrauterina y el nacimiento son evidentes en este pasaje. Las fantasías que pone en juego el poeta, para desembarazarse de la ilusión de la representación religiosa de la Iglesia, aceptan el doble sustento histórico que las constituyen. Por un lado, el creador literario está dispuesto a revivir, a recordar, dos vivencias que antes ya experimentó: el nacimiento y el bautismo para redimirse y dirigir su credo hacia la obra libertaria de Cristo. Por otro lado, el poeta reconoce en su propia existencia la herencia transmitida por la descendencia de Abraham. Se afinca un espacio en la descendencia familiar del "padre de muchos pueblos", asumiéndose como hermano de muchas otras personas, pero con el privilegio de parecerse a Isaac, quien es el heredero de todos los bienes de Abraham. El poeta hereda de la historia transgeneracional de Abraham el privilegio de cuidar de todos sus hermanos; aquellos que forjan las comunidades que constituyen al Pueblo. Ambos tiempos históricos de las fantasías esbozadas en el verso actúan como condiciones que toman la fuerza de la causa específica que despertó su interés por abandonar la fe. Esto lo explicó Pablo Apellidos en el pasaje de una entrevista ${ }^{2}$ que dio al diario La Discusión de Chillán a propósito del lanzamiento de El libro devorado. En ella comentó que

$[u] n$ verano estaba en el departamento de un amigo en Santiago y había una Biblia y de repente me puse a leer la Biblia y me iluminé (...) El libro es contra la iglesia como institución, contra la religión como imposición normativa, pero no contra la fe $(\mathrm{s} / \mathrm{n})$

Anteriormente se mencionó que las huellas impresionan y adquieren sentido de forma posterior, motivando al sujeto a hacer algo con ese despertar del recuerdo. La forma en que tramitó los montos de afectos fue dedicarse a

2 Nota de prensa "La apostasía que Pablo Apellidos transformó en Poesía" publicada el 12 de octubre de 2015 y disponible para su revisión en la dirección web del diario “La Discusión" http://h.ladiscusion.cl/index.php/vidaycultura/vidaycultura1110121213/ cultura631336175/49267-la-apostasia-que-pablo-apellidos-convirtio-en-poesia 
la producción literaria. Tomó en serio su creación, al igual que un niño su juego -nótese que en el verso analizado se considera un "niño iluminado"y se destinó a construir versos poéticos que funcionaran como puntales de ilusiones sustitutivas fuertemente energizadas por las fantasías. De esa manera, obtiene un goce, el juego de palabras poéticas pasó de ser un juego de duelo a un juego de placer [Lustspiel]. En la medida que renuncia a la función burocrática de su nombre y asume la función mesiánica, el poeta comparte el placer obtenido por imaginar un mundo nuevo, donde la perversa institucionalidad deja su lugar a la obra del auténtico llamado de Cristo: la esperanza que florece cuando se abandona lo que ata a lo funesto. Esto es lo que reivindica el creador literario, tal como lo reafirma en el poema treinta y nueve

Este es el fruto que he dado se me reconocerá por él.

Si mi fruto es bueno, y lo es ¿Cuál será el fruto de quiénes me llamen falso profeta?

Sabemos que un mal árbol no da buen fruto y que un buen árbol no da mal fruto

Sabemos qué se debe hacer con el mal árbol y si acaso el mal árbol también lo sabe ¿Por qué no se ha quemado (45)

La esperanza adviene como una sensación placentera porque el poeta realizó un duelo, una separación y desidentificación con el vértice ominoso de la herencia del nombre del apóstol Pablo. El desligue de los montos de afectos de la función burocrática y la reafirmación de la potencia mesiánica, de profeta de las enseñanzas de Jesús, mas no de las reglas de la institucionalidad religiosa, permiten que el creador literario realice una apostasía para renunciar a la marca de su bautismo, pero sin renunciar a las influencias de la historia de Cristo. En ella se reconoce como heredero de la tradición de Abraham y como hermano de otros miembros del Pueblo. El poeta tramita así su malestar y desprende montos de afectos placenteros que articulan su propuesta de esperanza. 


\section{PALABRAS FINALES}

Luego de que Pablo Apellidos presentó El libro devorado en la casa de Gonzalo Rojas de Chillán en la primavera de 2015, me acerqué a pedirle su firma. No solo cumplió con lo solicitado, sino que la acompañó con una glosa que reza como sigue

"José y Alba: Que el Jesús que murió en Bolivia guíe su camino hasta la revolución. Un abrazo. Pablo Apellidos, octubre de 2015"”

La glosa que imprimió en la primera página del libro refleja el producto de la invitación mesiánica articulada en su apostasía. Los versos evidencian una dura crítica hacia la institucionalidad religiosa, pero también le exige a sus representantes que comprendan los motivos que sustentaron su renuncia. De lo que se deshace es de la impronta burocrática que cierra filas con la estructura institucional de la Iglesia, relevando la causa defendida por Jesús a favor de su Pueblo. Pablo Apellidos no abandona la creencia, la ilusión, ni las fantasías que lo hacen tejer mundos nuevos en su actividad creativa. Más bien, se aleja de las consecuencias que la representación religiosa ha tenido en la constitución del mundo, se aparta de lo infame de sus acciones y se vuelca contra los defensores de la desidia. Critica duramente a los cómplices de las experiencias de abandono del ser humano y ofrece a cambio una reinvención, un reverdecer de las esperanzas sostenidas en la valoración de mesianismo que puede redimir a la humanidad.

Esta apuesta recuerda algunos pasajes de la obra de Erich Fromm $\mathrm{La}$ revolución de la esperanza: hacia una tecnología humanizada (1970 (2012)). En ella señala que la esperanza mesiánica se asienta en que los profetas ven la realidad presente exenta de las obnubilaciones a las que están sometidas otras personas. Por aquello, se sienten forzados a expresar sus ideas y ponen en palabras la articulación de sus creencias. Muestran alternativas para que los demás puedan elegir y dirigirse conforme a los planes trazados para su futuro. Con la entrega de El libro devorado como testimonio de su apostasía, el creador literario reafirma sus ideales y se desprende de un malestar que tuvo como fuente las marcas de traspaso de representaciones religiosas en el

Esta glosa fue ubicada en la primera página en blanco de "El Libro Devorado" que adquirí en octubre de 2015 cuando el poeta Pablo Apellidos lo lanzó en la casa museo de Gonzalo Rojas en Chillán. 
seno de su grupo familiar. Deja de ser Pablo el espadachín de la castración $\mathrm{y}$ del degüelle del pensamiento para reafirmarse como Pablo el gentil que es capaz de enarbolar en sus versos la defensa del valor humano. En palabras de Walter Benjamin (1940 (2009)) el mundo mesiánico defendido por el poeta

Sólo y primeramente en él hay una historia universal. Pero no en cuanto escrita, sino como la [historia] que se festeja. Este festejo está purificado de toda solemnidad. No conoce cantos festivos. Su lengua es prosa liberada, que ha hecho saltar los grilletes de la escritura (62)

En la renuncia a los grilletes adquiridos en el bautismo, Pablo opone a los cuarenta y seis libros del Antiguo Testamento sus cuarenta y seis poemas apóstatas. En ellos discurre un notable proceso de desanudar la marca de la transmisión burócrata de la religión, para finalizar comentando que

Salí de la palabra y vine al mundo, de nuevo dejo el mundo y vuelvo a la palabra (53)

Escapa de la palabra molesta estampada como arquetipo en su nombre apostólico, mira las consecuencias que ha dejado en el desarrollo de la humanidad la representación religiosa institucional, abandona ese mundo a través de la apostasía y regresa a la utilización de la palabra, a los versos de su creación literaria para invitarme a mí y a otros y otras a marcar nuestras vidas con la búsqueda de la redención.

\section{BIBLIOGRAFÍA}

Apellidos, Pablo. El libro devorado. Valparaíso: Caronte editores, 2015.

Benjamin, Walter. "Apuntes sobre el concepto de historia". La dialéctica en suspenso. Fragmentos sobre la historia. 1940. Santiago de Chile: LOM, 2009.

Freud, Sigmund. "Manuscrito L", Obras Completas. Volumen I. Publicaciones prepsicoanalíticas y manuscritos inéditos en la vida de Freud (1886-1899). Buenos Aires: Amorrortu, 1992. 289-292.

"Proyecto de una psicología para neurólogos", Obras Completas. Volumen I. Publicaciones prepsicoanalíticas y manuscritos inéditos en la vida de Freud (1886-1899). Buenos Aires: Amorrortu editores, 1992. 323-446.

“A propósito de las críticas a la «neurosis de angustia»". Obras Completas. Volumen III. Primeras publicaciones psicoanalíticas (1893-1899). Buenos Aires: Amorrortu editores, 1992. 117-138. 
"La herencia y la etiología de las neurosis". Obras Completas. Volumen III. Primeras publicaciones psicoanalíticas (1893-1899). Buenos Aires: Amorrortu editores, 1992. 139-156.

"Nuevas puntualizaciones sobre la neuropsicosis de defensa", Obras Completas. Volumen III. Primeras publicaciones psicoanáliticas (1893-1899). Buenos Aires: Amorrortu editores, 1992. 157-186.

"La interpretación de los sueños". Obras Completas. Volumen IV. La interpretación de los sueños I. Buenos Aires: Amorrortu editores, 1992.

"El creador literario y el fantaseo". Obras Completas. Volumen IX. El delirio y los sueños en la Gradiva de W. Jensen y otras obras (1906-1908). Buenos Aires: Amorrortu editores, 1992. 123-136.

“Análisis de la fobia de un niño de cinco años". Obras Completas. Volumen X. Análisis de la fobia de un niño de cinco años (el pequeño Hans) (1909). Buenos Aires: Amorrortu editores, 1992. 1-118.

"Historia de una neurosis infantil (caso del «hombre de los lobos»)". Obras Completas. Volumen XVII. De la historia de una neurosis infantil (caso del hombre de los lobos) y otras obras (1917-1919). Buenos Aires: Amorrortu editores, 1992. 1-112.

"Inhibición, síntoma y angustia". Obras Completas. Volumen XX. Presentación autobiográfica; inhibición, síntoma y angustia y ¿pueden los legos ejercer el psicoanálisis? y otras obras (1925-1926). Buenos Aires: Amorrortu editores, 1992. 71-164.

"El porvenir de una ilusión”. Obras Completas. Volumen XXI. El porvenir de una ilusión; el malestar en la cultura y otras obras (1927-1931). Buenos Aires: Amorrortu editores, 1992. 1-56.

"El malestar en la cultura". Obras Completas. Volumen XXI. El porvenir de una ilusión; el malestar en la cultura y otras obras (1927-1931). Buenos Aires: Amorrortu editores, 1992. 57-140.

Fromm, Erich. La revolución de la esperanza. Hacia una tecnología humanizada. México DF: Fondo de Cultura Económica, 2013.

Laplanche, J. y J-B. Pontalis. Diccionario de Psicoanálisis. Buenos Aires: Paidós, 2013. 